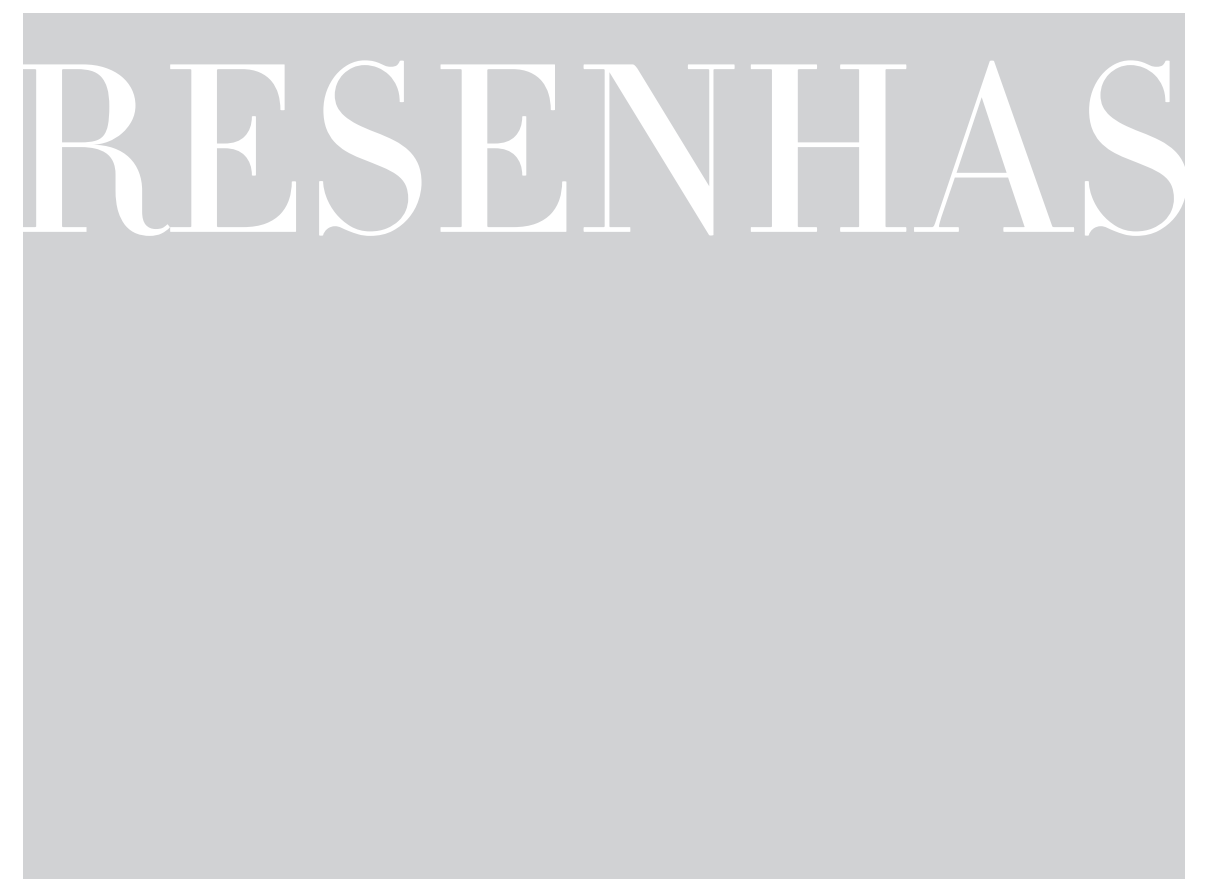

\title{
A FUNÇÃO EDUCATIVA DAS FAMÍLIAS NO CONTEXTO ITALIANO CONTEMPORÂNEO
}

https://doi.org/10.1590/198053145642

\author{
FLÁVIO SANTIAGO'
}

GLIGLI, Alessandra. Famiglie evo/ute: capire e sostenere le funzione educative delle famiglie plurali. Parma: Edizioni Junior, 2016

A construção do conceito de família sempre foi um campo de disputa de poder envolvendo relações sociais e culturais (LÉVI-STRAUSS, 1982; ENGELS, 2006). E a grave crise econômica italiana, que se prolonga há muitos anos, provocou sérias consequências sociais que são visíveis para todos e afetaram particularmente as famílias. O declínio nas taxas de emprego e a redução dos recursos econômicos atingiram a qualidade de vida e as relações interpessoais, influenciando diretamente os modos de constituição familiar. A fim de atravessar o momento atual, foi necessária uma estabilidade flexível, ou seja, uma capacidade de manter laços que corroborassem para lidar com mudanças e crises.

$\mathrm{O}$ entendimento do que seria a constituição de uma família tem sido colocado em xeque pelos movimentos sociais, feministas ou LGBTQI+, os quais, não só no contexto brasileiro, mas também no italiano, têm sido fortemente criticados pelos setores conservadores e religiosos. Estes afirmam que o questionamento estaria construindo uma “doutrinação" que serviria para "confundir a cabeça de crianças e adolescentes”, além de contribuir para “desestruturar a moral” das relações 
no âmbito familiar ao "desconstruir a maternidade e incentivar a prática do aborto” (BARREIRO et al., 2016, p. 228).

A partir desse contexto, Alessandra Gligli (2016), pesquisadora da Università di Bologna, aborda em seu livro essas tensões e mudanças, focando a discussão nas ditas "famílias evoluídas/flexíveis”, definidas pela autora como aquelas constituídas por suas livres escolhas, expressando um projeto conjunto que é arquitetado como uma intencionalidade ética e flexível, capaz de atravessar possibilidades de crise e de transformações, que inevitavelmente se apresentaram, sem perder a função educativa designada a essa estrutura social.

Para a autora, o amor romântico, monogâmico e heterossexual não é modelo único e suficiente para expressar o padrão de família, existindo outros arranjos familiares com a mesma função social. Não existe uma família igual à outra, e esse polimorfismo é produto de macroprocessos (culturais, sociais, econômicos, legislativos) e de revoluções antropológicas, ainda em andamento, que mudaram as coordenadas da vida familiar em relação ao que estávamos acostumados a conceber algumas décadas atrás. Em outras palavras, não é possível pensar em uma tipologia familiar padrão; essa singularidade nunca foi tão clara ou real.

Outro aspecto abordado é a dimensão pública da criação dos filhos. Por mais que o ambiente familiar seja um local de socialização primária das crianças, a educação não é, e nunca será, um assunto específico do âmbito privado dos casais, pois esse processo envolve esferas sociais que transcendem a relação entre a figura do casal e as crianças. Contudo, essa informação não diz respeito ao interesse de pais e mães sobre a criação dos filhos e filhas, como bem demonstra Gligli em seu livro; a maioria deles/as está interessada na criação e ansiosa para a construção de laços afetivos. O que a autora coloca em destaque é que essas relações ultrapassam a esfera do plano privado familiar e se constituem enquanto um campo do domínio das relações sociais da macroestrutura.

O processo que ocorre no contexto italiano tem resultado em uma redução progressiva dos investimentos nos sistemas de educação pública, o que enfraquece as oportunidades educacionais em algumas áreas do país, desencadeando uma permanência menor nos sistemas escolares para as novas gerações e uma reestruturação do trabalho de cuidado familiar com a atividade realizada fora, já que as crianças passam menos períodos nas escolas e creches. O próprio papel atribuído à mulher na maternidade está em transformação devido a mudanças sociais. Atualmente na Itália vemos muitas "mães de família”, que assumem essa função em razão da perda do emprego dos pais, que, por falta de escolha, passam a ocupar a posição social atribuída à "maternagem”, ficando responsáveis pelo cuidado do lar e pela educação das crianças, enquanto as mães assumem os aspectos relativos a atribuições sociais consideradas masculinas, como o gerencialmente do orçamento 
familiar. Também vemos homens italianos que querem dividir as tarefas domésticas e o cuidado de filhos e filhas, no entanto, não se trata de um movimento homogêneo no território nacional e é influenciado por muitas variáveis geográficas, sociais e culturais.

De qualquer forma, nos núcleos familiares italianos, ainda persiste uma cultura de sacrifício feminino e desengajamento masculino, com histórias e motivações complexas de analisar, o que afeta fortemente tanto o equilíbrio do casal quanto o plano educativo e a formação das novas gerações. É importante destacar que, na Itália, somente em 1975 ocorreu a reforma do direito familiar. Anteriormente a essa mudança, o quadro normativo falava em autoridade (masculina) e obediência (feminina), a lei previa a figura do "chefe de família" que tinha o poder de decisão sobre a vida de todos/as e a mulher era obrigada legalmente a seguir o marido onde quer que ele achasse adequado; essa lógica explicitava uma divisão rígida de papéis e funções atribuídos de acordo com o gênero.

As mudanças sociais dos últimos anos gradualmente colocaram em questão esse sistema de forma definitiva. Em decorrência das lutas provocadas pelos movimentos sociais, que desde os anos 1970 têm desafiado o patriarcado e as estruturas que legitimam a submissão feminina, vemos hoje as relações de gênero assumirem uma conotação mais democrática na Itália: as mulheres adquiriram maior autonomia e os homens se apropriaram de um papel historicamente inédito nas funções do cuidado, abrindo espaço para o "afeto da paternidade”. Esse novo sujeito masculino não é apenas capaz de cuidar do outro física e emocionalmente, mas também está cuidando de si mesmo, no sentido de aumentar sua consciência, sendo empático e colaborativo com os outros. Esse processo constituiu uma abertura da masculinidade ao compartilhamento e à comunicação, não apenas entre seus pares, mas também com os/as demais.

A forma pela qual as famílias se organizam é certamente uma variável importante, mas também o aspecto qualitativo da relação tem um impacto substancial nas funções ligadas a saúde e educação. O tão desejado bem-estar, que representa a essência de um sistema relacional que funciona, como coloca a autora, não é sinônimo de uma condição estática na qual não há perturbações, mas é caracterizado pelo dinamismo, porque brota de mudanças contínuas: é um sistema que, por assim dizer, goza de estabilidade flexível.

Dentro desse quadro, a autora traz para discussão a qualidade das relações educativas nas famílias diante dos novos cenários de maternidade e paternidade, os quais necessitam de uma busca de equilíbrio entre trabalho e cuidado familiar. Gligli também aborda as dificuldades normativas que os estilos parentais expressam e os problemas educativos ligados à "harmonia do casal", bem como o impacto da crise econômica e das novas tecnologias de informação nas relações educacionais. 
As famílias, durante toda a obra, são reconhecidas como células fundamentais da sociedade e como ambiente privilegiado das práticas educativas; contudo, a autora não esquece de destacar a existência de experiências interpessoais (extrafamiliares) que podem enriquecer o horizonte existencial dos sujeitos, a exemplo dos processos educativos vivenciados no ambiente escolar, no grupo de pares, etc. A pedagogia familiar se traduz em práticas educacionais e de treinamento principalmente em duas direções: ações educativas preventivas e a formação e fortalecimento das habilidades relacionais para com aqueles que interagem direta ou indiretamente com as famílias. Nesse sentido, torna-se fundamental o envolvimento dos genitores na vida extrafamiliar, já a partir das primeiras experiências das crianças na creche e posteriormente na escola.

Para Gligli, a relação entre família e escola/creche/pré-escola constitui a chamada "comunidade educativa", que tem por objetivo atuar no sentido do bem-estar das crianças. Nessa perspectiva, as famílias são consideradas parceiras ativas no processo de educação formal. No contexto italiano, as referências normativas e os documentos oficiais que tratam dessa aliança educacional são numerosos, tanto para a faixa etária de 0 a 6 anos quanto para as escolas de outros níveis. Entretanto, é importante frisar que a referência à cooperação entre sistema educativo e família é constante e transversal, porém, poucos documentos oficiais abordam a definição a ser tomada em um senso prático. A escola é solicitada a ser criadora de um processo complexo, como o cooperativo, mas não há ferramentas suficientes para isso, seja em âmbito material, seja no sociocultural.

Outra característica destacada pela autora é que muitos desses documentos enfatizam a "primazia educacional das famílias”, atribuindo-lhes o direito de assumir a responsabilidade pelas escolhas educacionais para as crianças: a partir dessa prerrogativa, os serviços escolares têm como função apoiar a educação familiar das crianças e não o contrário. Essa questão não é trivial, pois pode gerar interpretações que concebem a escola pública italiana como serviço à família, não à criança, e portanto pode reforçar a ideia de que os pais são apenas clientes, não construindo uma relação direta de troca e conexão para a construção do projeto pedagógico em conjunto.

A relação entre pais/mães e professores/educadores também passa a se constituir como ambivalente, provocando muitos pontos de desconfiança entre ambas as partes, o que evidencia a conquista da confiança não como um empreendimento individual de cada professor/educador para com os genitores. Isso porque, além do trabalho do indivíduo, os elementos sociais marcam essa relação e impulsionam comportamentos com base em normas e expectativas preexistentes da própria relação entre esses dois atores educativos. Para compreendermos essa relação 
também se torna fundamental pensar o quadro organizacional a partir das suas condições concretas que facilitam/atrapalham o estabelecimento e a manutenção de uma relação de confiança entre educadores e pais.

Em que pesem as críticas que podem ser tecidas a respeito das relações entre as famílias e as escolas, a autora aponta questões importantes que ultrapassam as características específicas do contexto italiano, estando presentes também em nossas escolas brasileiras. O livro, nesse sentido, ajuda-nos a perceber que problemas que envolvem a organização familiar e sua relação com o sistema educativo não são exclusivos do nosso contexto nacional, mas reverberações de um processo macroestrutural que atinge diferentes países com seus modos e especificidades próprios. O livro aqui apresentado coloca em foco as mudanças ocorridas na estruturação do contexto familiar italiano e aponta alguns entraves e especificidades das relações dessas famílias com o sistema educativo. A obra contribui para o debate educacional, principalmente, no que tange a pensar a escola como instituição pertencente a uma sociedade em constante mudança, o que reverbera na sua forma de organização e sistematização dos processos educativos.

\section{REFERÊNCIAS}

BARREIRO, Alex et al. Ideologia de gênero? Notas para um debate sobre políticas e violências institucionais. Temáticas, Campinas, v. 24, n. 47, p. 223-246, fev./dez. 2016.

ENGELS, Friedrich. A origem da familia, da propriedade privada e do Estado. São Paulo: Centauro, 2006.

GLIGLI, Alessandra. Famiglie evolute: capire e sostenere le funzione educative delle famiglie plurali. Parma: Edizioni Junior, 2016.

LÉVI-STRAUSS, Claude. As estruturas elementares do parentesco. Petrópolis: Vozes, 1982.

Recebido em: 22 JUNHO 2018 | Aprovado para publicação em: 20 AGOSTO 2018 
